\title{
O MÉTODO DOS TRABALHOS DE CONCLUSÃO DE PÓS-GRADUAÇÃO SOB O OLHAR DO DISCURSO DO MÉTODO
}

\section{THE METHOD OF THE FINAL WORK OF THE GRADUATION UNDER THE LOOK OF THE DISCOURSE ON METHOD}

\author{
Roberto Vilmar Satur \\ Doutor em Ciência da Informação \\ Professor do Departamento de Mediações Interculturais da UFPB \\ robertosatur@yahoo.com.br \\ Cláudio Pilar da Silva Júnior \\ Doutor em Administração \\ Professor do PPGA/UFPB \\ claudiopilaradm@gmail.com \\ Carlo Gabriel Porto Bellini \\ Doutor e Mestre em Administração \\ Professor do PPGA e do MPGOA - UFPB \\ cgpbellini@gmail.com
}

Recebido em: 26-04-2019

Aceito em: 03-07-2019

\begin{abstract}
Resumo: Este artigo trata de reflexões epistemológicas e de Pesquisas em Administração. Considerando a preocupação de diversos autores sobre a qualidade das teorias e das pesquisas em administração, buscou-se respaldo sobre o método, a ciência e a racionalidade na obra Discurso do Método de René Descartes. Surge então o desafio de verificar nas dissertações na área de finanças desse Programa se estas levaram em conta o que Descartes indicava como relevante enquanto princípio e método científico. Como conclusão, pode-se afirmar que o método de Descartes, mesmo que desconhecido por muitos, se fez presente em praticamente todas as dissertações analisadas.
\end{abstract}

Palavras-chave: Descartes; Método; Rigor; Pesquisa em Administração

\begin{abstract}
This article grew out of reflections on the epistemology and Research in administration. Whereas the concern of several authors on the quality of the theories and researches in administration, we sought support on the method, science and rationality in the work Discourse on Method by René Descartes. Then comes the challenge of verifying the dissertations in finance's area on this program if they took into account what Descartes indicated as relevant as a principle and scientific method. In conclusion, it can be stated that the method of Descartes, even if unknown to many, was present in virtually all dissertations analyzed.
\end{abstract}

Keywords: Descartes; method; rigor; Research in Administration.

\section{INTRODUÇÃO}

Este artigo nasceu de reflexões epistemológicas com resgate a autores clássicos da construção da cientificidade e discussão sobre o método, a ciência e a racionalidade baseados em Descartes no seu livro Discurso do Método. Surgiu, então, a ideia de verificar, em dissertações de Finanças do PPGA da UFPB defendidas no último triênio de avaliação do MEC/CAPES, ou seja, 2010-2012, e mais o ano de 2013, devido à atualidade - ou seja, os últimos quatro anos, se estes trabalhos levavam em conta o que Descartes indicava como relevante enquanto princípio e método científico.

Isso também decorre de discussões e leituras da disciplina que apontavam para os dilemas e certa crise que o desenvolvimento de teorias vem sofrendo, onde alguns autores chegam a apontar que as recentes teorias na maioria dos casos são fracas, ruins ou até más teorias. Além de que apontam para a verdadeira 
existência de um "vácuo" de novas boas teorias organizacionais nas últimas décadas. Fato que não seria por falta de disponibilidade e fácil acesso aos dados e informações, fruto do avanço tecnológico que agilizou tudo. Segundo essas constatações o problema estaria no rigor e relevância das pesquisas acadêmicocientíficas na área, que estaria com foco inadequado.

Por essa e outras razões, optou-se por recorrer aos clássicos do método científico para uma releitura do que se estava fazendo versus o que eles indicavam. Assim, nos coube estudar René Descartes, especialmente o seu livro Discurso do Método e posteriormente analisar as dissertações de finanças do PPGA da UFPB nessa perspectiva.

\subsection{METODOLOGIA}

O primeiro trabalho foi estudar o livro de Descartes e elencar pontos chave que ele aponta como relevante. Posteriormente foram o de verificar junto aos trabalhos do PPGA quais eram da linha de Finanças, em seguida fez-se a leitura e análise destes avaliando pelos pontos chaves elencados e finalmente a última etapa foi a de transformar isso em um texto em forma de artigo.

\section{REFERENCIAL TEÓRICO}

Primeiramente apresenta-se uma síntese da releitura do livro Discurso do Método, de René Descartes e, em seguida, alguns apontamentos de autores sobre as teorias organizacionais.

\subsection{O DISCURSO DO MÉTODO DE DESCARTES}

René Descartes (1596-1650) foi autor de muitas importantes obras, fundamentais para o avanço da ciência e muito conhecido pelo método cartesiano. Nossa atenção será dada ao livro Discurso do Método, cujo objetivo principal era a de valorizar a razão, a dúvida e o método como pré-requisitos da ciência, sendo dividida em seis partes, onde se faz "um misto de autobiografia com doutrinas para o bem da ciência com método, em busca na verdade, focado no racionalismo".

Em sua primeira parte, Descartes (1596-1650) estabelece o objetivo de "bem conduzir a razão e procurar a verdade nas ciências". Nesta parte, o autor faz algumas afirmações sobre a importância de ter sido "letrado" desde jovem, ou seja, ter estudado tudo o que os livros e as escolas the ofereceram, pois isso lhe permitiria avançar, valorizar o que era válido e descartar o que não servia, evitando ser enganado. Aprendemos a viajar nos livros e pelo mundo, ficando estrangeiros no nosso próprio local de vivência, pois nos diferenciamos dos demais. O melhor mesmo é o livro do mundo, conhecer outras culturas, outras formas de pensar, outras pessoas. (DESCARTES, 1996)

Na segunda parte, Descartes (1596-1650) remete para a importância de outra grande viagem: para dentro de si, se redescobrindo com a razão. Descobrir que uma pessoa pode fazer coisas brilhantes apenas com suas mãos (artesões) permite dizer que isso também cabe ao pesquisador. Para isso, muitas vezes, precisamos nos desligar da forma como muitas vezes fomos "bitolados desde criança", ouvindo nossa razão.

Assim, recomenda como método primordial da pesquisa um conjunto de quatro preceitos: "Optei por tão-somente quatro preceitos" (Descartes, 1996, p. 23):

$1^{\circ}$ ) não aceitar nada como verdadeiro se não se conhece a evidência disso (antes, toda a dúvida deve ter sido eliminada);

$2^{\circ}$ ) Dividir o problema em partes, de forma tão detalhada até onde seja possível, de modo a melhor entendêlo e resolvê-lo;

$3^{\circ}$ ) partir do mais fácil para o mais duvidoso, durante a pesquisa, de modo a ir aprofundando, pouco a pouco e com certezas do que está descobrindo, até descobrir tudo que se pode;

$\left.4^{\circ}\right)$ Sempre anotar tudo, revisar, ter a certeza que nada foi omitido.

Na terceira parte, Descartes (1596-1650) defende a "demolição" do que se tinha como verdadeiro até então para "edificar uma nova casa", em cima das descobertas, da razão. Mas, para não ficar sem teto, defende-se uma moral provisória de transição. Tudo isso para seguir as próprias ideias somente de coloca-las a prova, para não ter dúvidas. Optou pelo respeito às leis, religião e valores e ouvir os mais moderados. Também de não desistir no meio do caminho somente por que se sente um pouco perdido, seguindo em frente, pois o que virá deve ser melhor que ficar "perdido no meio da mata". Ainda a necessidade que temos de vencer a nós mesmos e não o mundo: nosso pessimismo, nosso desânimo, nossas incredulidades, nossos apegos, nossos preconceitos. 
Na quarte parte, surge à expressão mais famosa de Descartes (1596-1650): “Se penso, logo existo!". A ideia da separação entre mente e corpo, a ideia do controle da mente pela razão, pela racionalidade. A descoberta das imperfeições do ser humano, a existência do ser perfeito (Deus), a busca pela perfeição pouco a pouco, somente sendo possível pela descoberta. Para isso, precisamos levar a mente para um novo patamar, da racionalidade, e não mais somente imaginar e sentir, e sim, entender. Assim como o sonho pode ser apenas imaginação, muita coisa que se faz e em que se acredita enquanto acordado, podem ser enganosas. Precisamos focar na evidência da razão. A verdade precisa estar nos nossos pensamentos enquanto estamos acordados.

Na quinta parte, o autor deixa claro que não escreveu tudo que pensava por temer as consequências. Se tudo escrevesse, numa época onde qualquer ideia que não fosse agradável ao pensamento dominante, poderia representar condenação a fogueira.

$\mathrm{Na}$ continuação, diz que, se fosse feita uma máquina com todos os atributos de um macaco (um dos primeiros a imaginar um robô), não seria possível distingui-los. Entretanto, se fosse semelhante ao homem, seria possível distingui-los por dois atributos fundamentais que somente o ser humano tem: a capacidade do (1) diálogo orquestrado com o pensamento, e o conseguir (2) agir com a razão e a razão que o faz agir. E Descartes vai além, dizendo que estamos providos de alma racional (razão), e esse pensar racional não nasce conosco, é preciso criá-lo, desenvolvê-lo, não basta ter cérebro é preciso enriquecê-lo com conhecimento e racionalidade. Afinal, como nossa mente tem vida própria, nada leva a crer que tudo acabe com a morte do corpo, pois ela tem todas as condições para ser imortal.

$\mathrm{Na}$ sua sexta é última parte, o livro é rico em detalhes, dicas e argumentos. O medo da fogueira reaparece, o que demonstra que talvez ele tenha apenas publicado o que fosse possível e ainda assim cheio de receios. Contudo, isso não impediu de trazer importantes contribuições como a defesa veemente da socialização da pesquisa, e da pesquisa estar à frente do seu tempo, reservando-se ao direito de deixar para as gerações futuras as contribuições que fora obrigado a omitir para os de sua época, pois estes não o entenderiam.

\subsection{A TEORIZAÇÃO EM GESTÃO E OS DILEMAS DO PESQUISAR E PUBLICAR NA ÁREA}

Segundo Ghoshal (2005), a teoria da gestão muda o comportamento do gestor, pois esse começa a agir de acordo com essa teoria: eis o perigo da teoria ruim ou da má teoria. As más teorias ou teorias ruins destroem boas práticas de gestão. Nada é tão perigoso como uma má teoria. Sermões, pregações, desejos e esperanças não são teorias. São teorias erradas ou ruins que passam por verdadeiras. Isso tudo não é teoria, pois teoria tem que iluminar e explicar (GHOSHAL, 2005).

Faz três décadas que as teorias organizacionais têm sido dominadas por "meia dúzia" de argumentos e paradigmas, ainda dos anos 1970, não evoluindo depois disso (DAVIS, 2010). Das oito teorias existentes, que sem mantêm, seis são dos anos 1970. E os teóricos posteriores nem colocam essas teorias para confrontar, ver qual está melhor estruturada, que daria melhor resultado concreto na gestão das organizações, fazer seleção natural das "espécies" teóricas, não competem entre si para responder as mesmas perguntas e ver qual responde melhor.

Enquanto nas outras ciências as teorias vão e vêm, surgem e são eliminadas ou substituídas, ou evoluem; nas teorias organizacionais dificilmente uma teoria desaparece, prefere-se deixar cada uma se manter soberana dentro de uma linha de argumentos, num debate metateórico. Assim, não há pressão para eliminar teorias fracas e permitir que surjam outras fortes no lugar. As teorias se mantêm porque nenhuma foi negada e não porque são verdadeiras. Isso é fruto do conformismo dos novos pesquisadores apenas em publicar e reconfirmar questões óbvias dessas teorias e no máximo introduzir pequenos ajustes, pequenas evoluções.

Uma teoria forte tem poucas declarações conceiturais e constroe um caso logicamente detalhado, simples e interconectado. É conexão entre fenômenos, é respostas dos porquês, enfatiza a natureza da relação causal, ordena cronologicamente os eventos, investiga todos os processos e profundamente, junta os argumentos convincentes e logicamente interligados, explica, prediz, justifica, convence (SUTTON; STAW, 1995). Poucas publicações de gestão estariam inclusas nesse argumento.

Diversas pesquisas e publicações vêm focando apenas em referências, dados, lista de variáveis, esquemas, hipóteses e previsões, achando que isso é criação de teoria (SUTTON; STAW, 1995). Ademais, as revistas e PPGs contribuem para isso, pois é o que mais exigem. Uma boa teoria pode ser rejeitada 
simplesmente porque o editor não gostou de seu argumento. Deve-se levar em conta também que escrever, pesquisar, publicar e teorizar nas ciências sociais e comportamentais é difícil, levando-se em conta o trabalho do autor em fazer compensações entre generalidade, simplicidade e precisão além de ter de garantir que os argumentos são lógicos, consistentes e integrados.

Já segundo Ghoshal (2005), perdemos três décadas concentrando-nos em problemas de gestão e negativismo. Fruto de teorias ruins que precisam ser desligitimizadas e urgementemente reimplantar o pluralismo, a universalidade de pensamentos. As escolas de negócios perderam o gosto pelo pluralismo e se renderam ao pensamento dominante. A única forma de combater absolutismo ideológico é o pluralismo intelectual. Mas negar essas teorias dominantes implica pressão e desprezo dos seus seguidores. Refutar teorias dominantes não as desalojam, no máximo criam-se alternativas. Também é preciso saber que simplesmente seguir teorias dominantes não garante que isso nos tornará grandes contribuidores para um "mundo melhor", grandes pesquisadores. No máximo far-se-á um novo "puxadinho" na teoria dominante. E também é preciso saber que uma nova teoria efetiva somente se firma se um coletivo significativo começar a trabalhar nela.

Davis (2010) afirma que ficamos o tempo todo correndo atrás de teorias organizacionais gerais e precisas, e isso é inútil, ficamos no máximo "afogados num mar de dados" muitos deles convenientemente formados. Isso tem gerado teorias ruins ou fracas, que usam desenfreada quantidade de variáveis independentes que na verdade explicam tudo e nada ao mesmo tempo. Precisamos admitir as limitações das pesquisas, admitir teorias parciais, intermediárias, processos teóricos. É preciso desalojar a exigência das fundamentações teóricas que fundamentam tudo e nada ao mesmo tempo, das regressões infinitas para tudo e distinguir entre indicadores reflexivos e indicativos. Ainda segundo o autor nem o telescópio sobreviveria se tivesse que ser justificado com as teorias existentes na sua época.

Estamos reféns da "igreja" denominada rigor, que é quem diz como pode ser algo pesquisado e publicado; e das "fábricas" denominadas empresas e instituições financiadoras, e do "rei" denominado governo, que são quem financiam a pesquisa, e dizem o que pode e deve ser pesquisado e publicado (BELLINI et al., 2013). O pesquisador acaba ficando refém dessas "regras" e exigências. Assim a pesquisa fica comprometida.

Estamos na era do fetichismo pela estatística onde as teorias deram lugar para estudos de séries temporais rigorosas e muito boas, mas que não levaram a grandes evoluções teóricas. Apesar dos muitos dados disponíveis e analisados de diversas formas, a teoria organizacional se tornou menos precisa nas três últimas décadas. Da forma como está continuamos apenas nos "quase experimentos", nas "quase teorias", nas "subteorias". E continua-se o rigor da exigência da fundamentação teórica e metodológica que muitas vezes "bitula" a boa publicação e a boa pesquisa para algo mediano, pois não podem fugir de modelos prontos, limitadores. Pois se uma pesquisa estiver bem à frente do que já se sabe atualmente de nada servirá a atual revisão teórica. E assim vivemos um festival de dados e informações estatísticas rigorosas, mas com conclusões diversas e muitas vezes contraditórias (DAVIS, 2010).

A pesquisa e a teoria têm de dar uma resposta prática para um problema atual ou apontar para o futuro (PEARCE e HUANG, 2012a). Para a pesquisa ou teoria ser aplicável algumas condições são indispensáveis: - Profissionais participando e analisando; - Resultados evidentes e claros; - Deixar claro como os leitores devem usar e aplicar esses resultados; - Explicar bem o contexto do estudo e da aplicação; Evidenciar se os resultados são consistentes na prática. O problema, segundo Pearce e Huang (2012a), é que tem havido uma mudança clara das publicações e pesquisas para o não acionável em termos de resultados e forma de publicação.

Isso tem levado a uma dicotomia: enquanto o aluno quer cada vez mais temas aplicados a negócios, nossos pesquisadores querem cada vez abstrair e complexar (caminhos desencontrados). Parece que quanto mais rigorosa a pesquisa menos relevante ela fica, afirmam. Complementam dizendo que se os jornalistas, os profissionais, os professores e os alunos de gestão acham nossas pesquisas cada vez menos interessantes, para quem estamos pesquisando? Finalmente alertam que talvez algo mais grave esteja acontecendo: a pesquisa não está sendo relevante por que os pesquisadores não estão sabendo ao certo o que é relevante em administração; ou talvez por que o incentivo para pesquisa relevante é menor; talvez por que a forma de pesquisar atual dá menos trabalho; talvez porque a maioria dos pesquisadores de gestão nunca entraram numa empresa real; talvez por que alunos dos programas de pós-graduação "são convidados a mergulhar na conversa erudita", mergulham na teoria e esquecem a prática. Ainda, estes estudantes são pressionados a 
publicar logo no seu início de curso sem ainda estarem "sofisticados" para isso. Além disso são pressionados a publicar em revistas ponta onde a falta de aplicação prática no artigo não é motivo de reprovação. Ainda, fazer trabalho aplicado e aplicável é muito mais difícil e trabalhoso, logo menos atraente. Como as universidades e os PPGs precisam ranking, eles tem pressa por produção, pressionam para tal e isso exige mais publicação, em quantidade. Como resultados é cada vez maior o número de publicações, dissertações e teses com pouca ou nenhuma importância prática. Ou seja, numa analogia poderia-se dizer que "aumentou o número de jogadores médios e o número de partidas, mas reduziram-se os craques". No final predomina uma situação onde o "mediano é louvado". (PEARCE E HUANG, 2012a).

Já Stewart e Barrick (2012) dizem não acreditar que os editores e pesquisadores de hoje são mais fracos que os do passado e nem que eles não se preocupam com pesquisas e publicações que enfoquem o prático. Para tal posicionamento, utilizaram o estudo de Palmer et. al. (2009), pois estes pesquisaram e apresentaram resultados que diz que a relevância do acionável (possibilidade de aplicar na prática) das pesquisas e publicações cairam de $80 \%$ nos anos 50 e 60 para 30\% nos anos 70 e voltou para $75 \%$ em 2004 . Stewart e Barrick (2012) ainda afirmam que não se pode simplificar estudos complexos que precisam considerar as diversas relações das organizações. Adotar modelos mais simples é válido didaticamente mas arriscado levando em conta a imprecisão que pode levar. Modelos não complexos em situações complexas, que é o ambiente da gestão, podem levar a conclusões incapazes de orientar ações. As boas pesquisas não estão comunicando como devem, nem no resumo e nem para o público, isso sim precisa ser revisto.

Bellini et al. (2013) explicam que isso acontece por conta da necessidade do rigor metodológico e padrões de publicação atual de pesquisa que está transformando o pesquisador em alguém negligente sobre a realidade, sobre a aplicabilidade prática. Afinal, a maioria dos pesquisadores são acadêmicos e estes são pressionados a ter produtividade, pois somente isso contará no seu currículo e na Instituição de Ensino Superior (IES). E continuam dizendo que para piorar a situação ainda existe o fato de profissionais e acadêmicos se acharem diferentes, onde somente o que seu lado faz é relevante e acham outra parte dispensável, logo não compartilham ações e descobertas.

Uma boa pesquisa deve gerar nova e útil informação para ensinar, deve trazer benefício de aprendizagem para o professor e para a interação com estudantes e profissionais e precisa agregar conhecimento útil para quem estuda ela (BELLINI et al., 2013). Enquanto isso não acontecer, o professor, o aluno e o profissional vão continuar se baseando no que dizem clássicos "panfletários gurus", que fazem livros de centenas de páginas e falam de tudo generalizadamente e deixando de lado as publicações recentes. Os órgãos que medem a qualidade das publicações das revistas e dos pesquisadores poderiam colaborar usando como medida a quantidade de vezes que essas publicações foram usadas em sala de aula e no mercado por profissionais. (PEARCE e HUANG, 2012b).

Segundo Davis (2010), talvez devêssemos suspeitar de que as organizações não comportem teorias precisas. Talvez porque que teorias organizacionais não são uma ciência experimental. Talvez porque séries temporais não resolvem o problema em teorias organizacionais. Talvez porque medimos variáveis dependentes pelas independentes, mas as dependentes também influenciam as "independentes", como medir o influenciado se este também influencia. Talvez por as teorias organizacionais serem apenas quaseexperimentos, ou quase-teorias, ou teorias fracas: qualidade total, reengenharia, teoria da agência e outras. Talvez porque as organizações não podem ser tratadas como objetos naturais e não cabem métodos da ciência natural. Talvez porque a anomalia funcional (instrumentos e ferramentas: "teoria do caminhão") são muito limitadas para explicar a organização. Talvez porque, como os biólogos não podem prever com precisão exata o que as espécies farão daqui a 50 anos para sobreviver com mais cinco graus de temperatura média; o mesmo talvez valha para as teorias organizacionais e as organizações, pois estas também são instáveis e mutantes ao longo do tempo e isso não se "cura" com estatísticas, modelos ou teoria específica. Talvez porque a organização faz parte do capitalismo que favorece a novidade que é algo imprevisível e trabalha sob a lógica da especulação. Talvez porque temos que admitir que as teorias não sejam gerais e sim parciais e limitadas, com algum valor, dentro de seu limite.

Como se pode ver, não existe consenso, tão-somente algumas indicações sobre o que está se fazendo atualmente enquanto pesquisa e publicações e sua relevância na teoria das organizações. Talvez tudo isso explique um pouco o porquê de o presente artigo haver optado pelo resgate do que Descarte considera relevante enquanto método para uma boa pesquisa. 


\section{ANÁLISE DAS DISSERTAÇÕES SOB A ÓTICA DO DISCURSO DO MÉTODO.}

O presente estudo, em sua etapa final teve por objetivo analisar as dissertações vinculadas ao PPGA da UFPB, da linha de pesquisa de Finanças, que foram defendidas no último triênio de avaliação do MEC/CAPES (2010/2012) e mais o ano de 2013 pela atualidade tendo por base os pensamentos defendidos por Descartes, na sua obra Discurso do Método.

Os trabalhos analisados são apresentados no Quadro 1:

Quadro 1: Identificação dos Trabalhos Analisados

\begin{tabular}{|l|l|l|}
\hline Ano & Título & Autor(a) \\
\hline 2011 & $\begin{array}{l}\text { A influência do índice book-to-market e do roe na explicação dos retornos das ações } \\
\text { brasileiras. }\end{array}$ & $\begin{array}{l}\text { CORDEIRO, } \\
\text { R.A. }\end{array}$ \\
\hline 2012 & Aplicação do modelo alternativo de três fatores no brasil. & SILVA, C. P. \\
\hline 2013 & $\begin{array}{l}\text { Precificação de opções sobre contratos futuros de boi gordo na bm\&fbovespa: um estudo } \\
\text { das volatilidades }\end{array}$ & PONTES, T.T.S \\
\hline 2013 & $\begin{array}{l}\text { A influência do market timing e do estágio do ciclo de vida na realização de ofertas } \\
\text { públicas de ações. }\end{array}$ & COSTA, V.S.I \\
\hline 2013 & Crescimento do ativo e retorno acionário: evidências do mercado brasileiro. & SILVA, S.C.S \\
\hline
\end{tabular}

Fonte: dados da pesquisa

Observa-se que, no ano de 2010, não houve dissertação defendida, fato que pode ser explicado pela vinculação dos docentes ao programa de pós-graduação naquele ano. Adicionalmente, verifica-se que há um aumento no número de trabalhos concluídos ao decorrer dos anos e que os assuntos estão relacionados a temas atuais como: modelos de precificação, estratégias de investimento, estudo de anomalias e estudo de opções.

Para a análise das dissertações, optou-se pela utilização das quatro regras estabelecidas pelo método proposto por Descartes, em seu livro Discurso do Método, mais duas questões relacionadas ao tema. Os pontos analisados são apresentados a seguir:

1. Estabelece um cenário provisório inicial (contexto inicial antes da pesquisa).

2. Somente acolhe alguma coisa como verdadeira após conhecê-la de maneira evidente (Regra da Evidência).

3. Conduz em ordem os pensamentos, começando pelos objetos mais simples e mais fáceis de conhecer, para subir, pouco a pouco, como por degraus, até o conhecimento dos mais complexos compostos (Regra da Síntese).

4. Decompõe o problema em tantas parcelas quantas forem possíveis (Regra da Análise).

5. O trabalho realiza desmembramentos tão complexos a ponto de estar certo de nada ter omitido. (Regra do Controle)

6. Prioriza a aplicação da racionalidade

Pela análise das dissertações, foi possível constatar que há uma preocupação em fazer uma contextualização dos temas abordados, que cada trabalho, com seus temas em particular, fizeram uma condução do leitor até o ponto atual da pesquisa, facilitando assim a compreensão do tema pesquisado.

O segundo ponto analisado apresenta uma maior dificuldade de investigação, pois o fato de reconhecer algo como verdadeiro é muito intrínseco do pesquisador. A simples explanação dos tópicos nas dissertações pode ser fruto do conhecimento do mesmo, ao se aprofundar em sua pesquisa, ou pode ser resultado de indicações dos seus orientadores, fazendo com que os tópicos expostos nos trabalhos sejam meras reproduções de assuntos já trabalhados na área, induzindo o pesquisador a acha-las verdadeiras. Nesse sentido, a análise da regra da evidência, que consiste em tomar por verdadeiro o que for claro e distinto, sem a presença de dúvidas, poderá ser observada com mais profundidade com a aplicação de outras metodologias.

Em seguida, analisou-se a estrutura das dissertações quanto à regra da síntese. Neste ponto, observou-se como a ordem dos pensamentos, bem como do trabalho desenvolvido foram apresentados ao seu público alvo. Constatou-se que todas as dissertações apresentaram um bom nível de encadeamento dos pensamentos. Isso pode ser alcançado por meio de um levantamento histórico das pesquisas realizadas na 
área que conduziam o leitor aos acontecimentos da época, além de proporcionarem um posicionamento do mesmo frente às pesquisas desenvolvidas.

Quanto à regra da análise, ou seja, a divisão dos nossos problemas em um grande número de partes a fim de a solucionarmos de uma melhor forma, observa-se, em geral, uma moderada análise dos resultados. Com a utilização dos computadores e das técnicas estatísticas há uma enorme variedade de procedimentos possíveis de serem realizados nos dados disponíveis, no entanto, apenas os procedimentos necessários ao alcance do objetivo geral das pesquisas são realizados.

A última regra do método de Descartes é a realização do número máximo possível de enumerações, desdobramentos e revisões com a finalidade de não "deixar escapar nada". Contudo, como exposto anteriormente, verificou-se que há uma limitação dos procedimentos no alcance do objetivo geral. Nesse sentido, verifica-se uma limitação dos achados que são postergados para publicações futuras, ou seja, o alcance do objetivo seria a principal importância das pesquisas. Como estamos preocupados com muitas publicações, novas observações ou resultados que poderiam ser alcançados em um único trabalho são convertidos em diversas frações.

Por fim, analisou-se a aplicação da racionalidade nas pesquisas, ou seja, alcançar o conhecimento por meio da razão. Em geral, as dissertações utilizam-se de recursos e modelos estatísticos, matemáticos e econométricos indicados pela literatura, evidenciando a prioridade pela racionalidade.

\section{CONCLUSÕES}

Este artigo nasceu de reflexões epistemológicas sobre a pesquisa, especialmente em Administração, e aplicadas, nesse estudo, ao PPGA da UFPB, após discussão sobre o método, a ciência e a racionalidade baseados em Descartes no seu livro Discurso do Método. Adicionalmente, teve por objetivo analisar as dissertações vinculadas ao PPGA da UFPB, da linha de pesquisa de Finanças, que foram defendidas no último triênio de avaliação do MEC/CAPES (2010/2012) e mais o ano de 2013, pela atualidade, tendo por base os pensamentos defendidos por Descartes, na sua obra Discurso do Método.

Observou-se que as dissertações analisadas apresentaram uma boa contextualização, deixando bem claro o objetivo da pesquisa. Além do mais, verifica-se o cuidado de levantar hipóteses e somente emitir posicionamento depois dos resultados serem testados, inclusive apresentando casos de rejeição de hipótese iniciais estabelecidas.

Ademais, observou-se o desdobramento das obras em diferentes partes, porém não é possível dizer categoricamente que novos desdobramentos não possam ser realizados. Além da presença constante da racionalidade nas pesquisas com a utilização de recursos e modelos estatísticos, matemáticos e econométricos indicados pela literatura.

Em decorrência da análise das dissertações, pode-se afirmar que o método de Descartes, mesmo que desconhecido por muitos, se fez presente em praticamente todas as dissertações analisados. Evidenciando não apenas a transmissão do conhecimento, mas gerando novas e úteis informações para o ensinar, além de agregar conhecimento útil para quem estuda ela (BELLINI et al., 2013). Talvez essa geração de novas e úteis informações e conhecimento presente nos trabalhos PPGA/UFPB e detectados também na sua área de Finanças explique parte do contínuo crescimento do referido PPGA, nas suas últimas avaliações, junto a seus órgãos avaliadores.

\section{REFERÊNCIAS}

BELlinI, C. G. P., DANTAS, G. F. M., PEREIRA, R. C. F. Are We Still Talking to Ourselves? An Analysis of the Introspective Information Technology Field by Brazilian Experts. International Journal of Human Capital \& Information Technology Professionals, v. 4, n. 3, 2013.

DAVIS, G.F. Do theories of organizations progress? Organizational Research Methods, v. 13, n. 4, p. 690709, 2010.

DESCARTES, R. (1596-1650). Discurso do método. São Paulo: Martins Fontes, 1996. 
GHOSHAL, S. Bad management theories are destroying good management practices. Academy of Management Learning \& Education, v. 4, n. 1, p. 75-91, 2005.

PALMER, D., DICK, B., FREIBURGER, N. Rigor and relevance in organization studies. Journal of Management Inquiry, v.18, p. 265-272, 2009.

PEARCE, J.L.; HUANG, L. The Decreasing Value of Our Research to Management Education. Academy of Management Learning \& Education, v. 11, n. 2, p. 247-262, 2012a.

PEARCE, J.L.; HUANG, L. Toward an Understanding of What Actionable Research Is. Academy of Management Learning \& Education, v. 11, n.2, p. 300-301, 2012b

STEWART, G.L.; BARRICK, M.R. The folly of using research-lacking rigor as a call to action. Academy of Management Learning \& Education, v. 11, n. 2, p. 278-284, 2012.

SUTTON, R.I.; STAW, B.M. What theory is not. Administrative Science Quarterly, v. 40, p. 371-384, 1995.

WEICK, K.E. What theory is not, theorizing is. Administrative Science Quarterly, v. 40, p. 385-390, 1995. 